\title{
MEDIA EXAGGERATION AND INFORMATION CREDIBILITY: QUALITATIVE ANALYSIS OF FEAR GENERATION FOR COVID- 19 USING NVIVO
}

\author{
Sahil Gupta \\ Department of Management Studies \\ IMS Ghaziabad University Courses Campus, Ghaziabad \\ Jyotsna Sharma \\ Department of Management Studies \\ Asian Educational Institute, Patiala \\ Dr. Muhammad Najm \\ Assistant Professor, Al-Falah University, Dubai, UAE \\ Siddharth Sharma \\ Assistant Professor \\ Amity School of Communication \\ Amity University Madhya Pradesh, Gwalior, MP
}

\begin{abstract}
Present world is information-driven. News, information, facts, figures, data are the few terms which are pedalling the wheels of the present life and human being too. The digitalisation has transformed the media in different ways. Apart from the traditional media platforms like radio, newspaper, magazines, and television, the new and speedy news delivery platforms has made the information accessible in a few seconds. The online platform like Instagram, Twitter, Facebook, WhatsApp, and various other social media, has transformed the people behaviour and expectations. Now the information can be accessed, obtained anytime and anywhere. Media has played a tremendous part in Covid times too. It has helped to spread the information about this deadly infectious very quickly. Almost every media platform is bombarded with ample information regarding Covid updates like new cases, deaths, number of tests conducted, recovery rates, precautions to be followed etc. People tend to believe every piece of information coming their way. It has been difficult to differentiate that which chunk of information is to be trusted and which is fake. This paper has presented the respondents sentiment regarding the information which they have come across Covid times. The qualitative analysis has been conducted using NVIVO 12 to extract the respondents viewpoint about the exaggeration of media on coronavirus disease.
\end{abstract}

Keywords: Covid-19, Information, Sentiment Analysis, Thematic Analysis, Nvivo

\section{INTRODUCTION}

Media has a very important role to play in making the news acceptable to the audience. News creates an extreme effect on mind, memory and leaves an impression that what is being presented to them is correct(Castillo et al., 2011). The coronavirus disease outbreak in China (COVID-19) has created an imbalance in daily lifestyle. On the day of 11th February 2020, WHO named it as Coronavirus: COVID19 and on March 11, 2020, WHO had declared this a pandemic (Pandey, 2020). The upcoming and latest news has caused a greatest social impact among people.

The news of deaths because of COVID-19, the geographical expansion of the same across the globe, declining prices of crude oil, stock exchange fall, cancellation of many nationals and international political events, sports events, business meetings or summits, cancellation of flights and limited movement across national or state boundaries, the updates regarding government instructions and precautionary measures to save the nationals from this virus etc has caused a panic among populations(Sadhna et al ,2020 ; Mejia et al., 2020; Slater, 2008). In this situation of the pandemic, it is the prime responsibility of the media, either social or print / television to present credible information to its audience.

The type of news received has a huge influence on a person (Mustafaraj \& Metaxas, 
2017; Yuan, 2011). The news can be hard or soft. The relevant point is that whether the news received is credible or not. True, exact, and accurate news must reach to people. There is numerous literature available which discuss the contribution of nature and type of news(Slater, 2008; Tang et al., 2014; Yuan, 2011; Zubiaga et al., 2018), media exaggeration(Boukes \& Vliegenthart, 2017; Castillo et al., 2011; Jacobson et al., 2020; Mejia et al., 2020) , community influence (Du Plessis, 2017; Mustafaraj \& Metaxas, 2017) in considering a news relevant. This study is an attempt to build a model around those factors collectively that all these contributes to make the information credible (R et al., 2020; S Aral, 2013; Tacchini et al., 2017) which results in fear generation(Mejia et al., 2020; Reer et al., 2019).

\section{REVIEW OF LITERATURE}

The nature of news leaves a huge effect on the perceptions of the people. All these contribute to influence the community beliefs, thoughts, and perceptions and hence the much talked or discussed news or information seems to be accurate and true((Mustafaraj \& Metaxas, 2017; Yuan, 2011; Zubiaga et al., 2018). Throughout this year the COVID-19 is muchtalked about news. Every channel, print media, online media, is showing this news on priority. However, the type of news and time spent on the reading the information and news also influences the population.

The daily updates regarding the rising number of cases, death rate, active cases, and recovered cases are being shown (Mejia et al., 2020; Pandey, 2020). The audience gets abundant updates regarding this subject. Many times the news can be true or not (Covid19: Misinformation, Fake News on Coronavirus Is Proving to Be Contagious - More Lifestyle Hindustan Times, n.d.; Ruchansky et al., 2017; Zubiaga et al., 2018). Hence, willing or unwillingly, the audience receives huge information. This leads towards the belief that whatever is being proposed to the audience is correct and ultimately, it shifts towards the development of credibility of the information for specific news.

$\mathrm{H}_{1}$ : Interest and time spent relates positively to Information credibility of news related to COVID: 19

It's a by and large observed phenomena that news is measured to be credible if it is much talked about in the society or community(Mustafaraj \& Metaxas, 2017). Community constitutes of health professionals, family friends or every member of the contact who has an influence on a person( (Jeffres et al., 2007; Mejia et al., 2020). Also, the news which is flashed again and again on the television channels or on social media platforms. Fake news is an act of misleading the news by an act of digital deception(Aldwairi \& Alwahedi, 2018; Mosinzova et al., 2019). The community has a significant role to play in the acceptance of news. The community comprises social networks, groups, friends etc(Guille et al., 2013; Jeffres et al., 2007; Ruchansky et al., 2017; Slater, 2008). The information in print media is still verified and tested and based on the evidence but the information shared on online media spread much faster than any other media platform and is not verified, tested and many times full of false claims. (Aldwairi \& Alwahedi, 2018). So, there is no second thought that community influence the authenticity of the news. It is believed that if someone is talking so much about a topic then there must be a valid point in it.

$\mathrm{H}_{2}$ : Community influence relates positively to Information credibility of news related to COVID: 19

Further, it is no denying fact that fake news leads to cause fear among people(Mejia et al., 2020). The media should understand its responsibility. Fake news creates misconception and fear.

The overstatement or amplification of the news by media also creates a higher amount of impact on the peoples' mind to take the news to be true and reliable(Chen et al., 2015). There are many precautionary steps that are supposed to be taken for the prevention of COVID-19, but besides there are convinced misconceptions or dissemination of information which cause insecurity among the people. Such type of news generates fear among people.

$\mathrm{H}_{3}$ : Exaggeration of media relates positively to Information credibility of news related to COVID: 19

There are certain factors that contribute towards the credibility of news. Credible news 
depends upon the reliable sources of collection of data, facts and figures(Castillo et al., 2011; Nguyen et al., 2012; Wang, 2017). Also, it is the audacity of the journalist and the concerned media platform how efficient they are to portrait the truth. The more credible the news users believed a medium to be, the higher the odds were for them to include it in their news media repertoire(Yuan, 2011). Social media platforms like Twitter, Instagram, youtube, WhatsApp etc has a huge impact on its audience (Boukes \& Vliegenthart, 2017).

Rumours and fake news cause disturbances. It hampers the genuineness of the news. The news which are being plashed on social media is usually questioned about its credibility, quality and truthfulness(Chen et al., 2015; Farajtabar et al., 2017). Information is being made credible if it is gathered from reliable resources, if someone has eye-witnessed it or some high profile agency is involved in the procurement of the information. So it is extracted from the above discussion that exaggeration of media, community influence and time spent on news leads to make news and information credible. This further leads to the generation of fear among the population. The fear can be less, more or no fear. But yes, there is no second opinion that information credibility causes a fear regarding that news.

$\mathrm{H}_{4}$ : Information credibility of COVID 19 news positively relates to the Generation of fear among people.

From the above discussion, the present study tries to establish that the above discussed factor collectively contributes towards the generation of fear. The fear develops because the perceived, received or heard news seems to be true to a great extent. The study makes an attempt to study that the credibility of news is liked to generation of fear. The underlying factors like interest in news, time spent in news, the influence of community, exaggeration of media also contributes towards the credibility of news which ultimately links to the generation of fear.

\section{RESEARCH METHODS}

This study is based on mixed methods research design (Schoonenbooma, Burke, Johnson, \& Froehlich, 2017). This was conducted by doing a comprehensive study on the role of media for information sharing. The theoretical foundation of the survey is based on secondary sources such as research papers, articles, magazines and articles on patient's expectations and satisfaction, for this purpose databases like EBSCO, ProQuest was used. The Study is both exploratory and descriptive in nature (Sharma and Gupta, 2020).

\section{Nature of Data:}

For this study, convenience and random sampling were implemented. To start with initially, the respondents were chosen on the convenience sampling. Further from responses collected from preliminary respondents, then referrals were taken from them.

\section{Source of Data and Period of Analysis:}

Out of 23 interviews, a total of 18 responses were taken into consideration for final analysis. Incomplete and ambiguous voice responses were excluded from the study. This study was conducted during the months of June to August 2020.Samples were taken from leading private and government Universities and hospitals of North India.

\section{DATA ANALYSIS}

The analysis was done in 2 phases, initially The theoretical foundation created and in the second phase of the study, data was collected by an In-depth interview. Responses from the interviews was transcribed and cleaned and were imported to the NVivo. In this study, transcription feature was not used, and all transcription was done manually using MS word. Initially, Data Cleaning was done. Stop words were declared and punctuation marks were removed.

In the second Stop Node were declared on the basis of questions. All the Responses of same questions were anchored on similar Node. To start with, Word Clouds were generated by declaring the Stop words which helped in extracting the useful content for the analysis. Further Sentiment analysis and Thematic analysis were done to generate the Sentiment and Themes using the Autocode feature.

\section{RESULTS AND DISCUSSION}

The qualitative data analysis has been selected for the research. It includes the word clouds, sentiments analysis and thematic analysis. This shows the views and thoughts of the respondents for the certain subject. The NVivo 12 is used for conducting qualitative analysis. 
a) Word clouds Analysis:

$\mathrm{H}_{1}$ : Interest and time spent relates positively to Information credibility of news related to COVID: 19

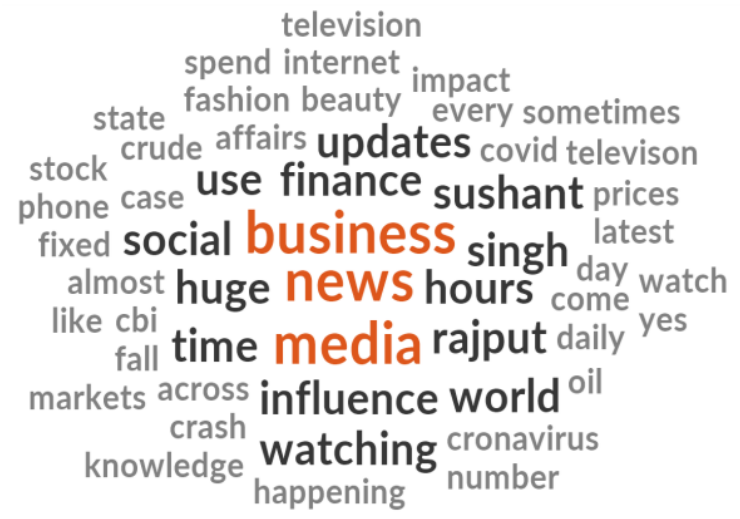

Figure 1: Interest and Time Spent

The word cloud depicts the kind of news which the respondent has come across during Covid-19 times. It has clearly pin points that respondents have spent their time on news related to coronavirus, business, finance, stock market etc. Also it is observed that crash of stock market; fall in crude oil prices, CBI for Sushant Singh Rajput has also got respondents attention.

$\mathrm{H}_{2}$ : Community influence relates positively to Information credibility of news related to COVID: 19

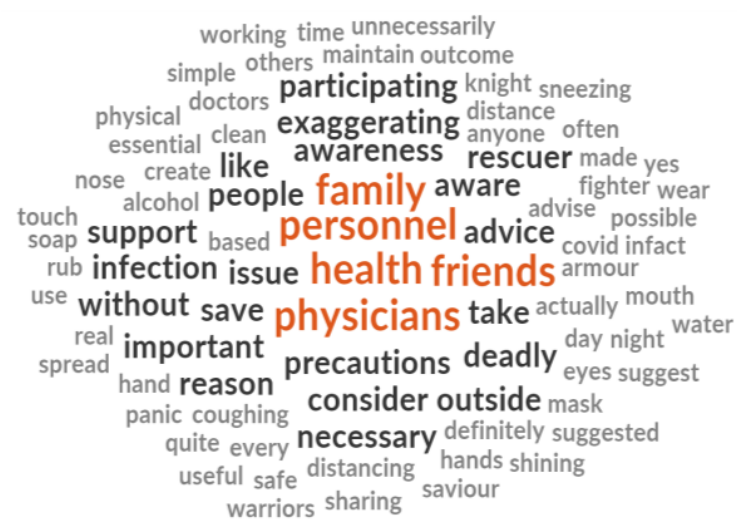

Figure 2: Community influence

The word cloud indicates that community has huge influence on the credibility of information. As the family, health physicians, friends are the most highlighted words in the clouds. Further precautions, awareness, infection support, advice indicates that the all the concerned person have their concerns regarding the spread of coronavirus infection as they advise the respondents to be aware of the deadly infection and take the necessary and possible precautions while moving outside and be safe.

$\mathrm{H}_{3}$ : Exaggeration of media relates positively to Information credibility of news related to COVID: 19

$$
\begin{aligned}
& \text { newspaper } \\
& \text { television display magazine } \\
& \text { media accurate donot wrong } \\
& \text { yes feel information }{ }_{\text {hard }} \\
& \text { radio exaggerating many } \\
& \text { working chance issue covid } \\
& \text { reporters lot channels journalist } \\
& \text { trust displayed social }
\end{aligned}
$$

\section{Figure 3: Exaggeration of media}

It has been inferred from the word cloud that the television, radio, newspaper, magazines and various channels has displayed many hard issues related the coronavirus which has exaggerated accurate information regarding Covid.

$\mathrm{H}_{4}$ : Information credibility of COVID 19 news positively relates to Generation of fear among people.

$$
\begin{gathered}
\text { trustworthy } \\
\text { totally reality television } \\
\text { relevant everyone platform } \\
\text { people ikelievable etc online } \\
\text { credible information different } \\
\text { whether answer media among } \\
\text { popular although news yes facts twitter } \\
\text { reliable believe facebook based provide } \\
\text { time directly maximum check social } \\
\text { number comment ractual } \\
\text { section opinion radio } \\
\text { traditional }
\end{gathered}
$$

\section{Figure 4: Fear Generation}

The word cloud has depicted that people in reality believe the factual, reliable, and credible news. The information is provided directly by various sources radio television, and many popular different online platforms like twitter, Facebook, social media etc.

Although people expresses that maximum information provided to them is believable 
and trustworthy. Also at times, their opinion is directly influenced by the comments shared in the comment section on social media.

\section{b) Sentimental analysis}

Table 1: Sentiment Analysis

\begin{tabular}{|c|c|c|c|c|}
\hline Codes & 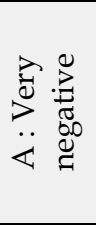 & 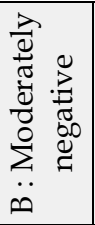 & 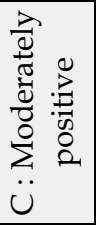 & 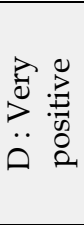 \\
\hline $\begin{array}{l}1 \text { : Communication } \\
\text { from health } \\
\text { professionals, family, } \\
\text { and friends }\end{array}$ & 1 & 0 & 0 & 0 \\
\hline $\begin{array}{l}2: \text { Exaggeration of the } \\
\text { media }\end{array}$ & 1 & 0 & 0 & 2 \\
\hline $3:$ Generated fear & 1 & 2 & 6 & 1 \\
\hline $\begin{array}{l}4: \text { Information } \\
\text { Credibility }\end{array}$ & 0 & 0 & 0 & 1 \\
\hline $\begin{array}{l}5: \text { Interest and time } \\
\text { spent in news }\end{array}$ & 0 & 1 & 1 & 0 \\
\hline
\end{tabular}

The sentimental analysis table indicates that role of Communication from health professionals, family, and friends is very negative. The Exaggeration of the media had a positive influence in create awareness regarding the Covid-19.

The generated fear has moderately positive impact on the respondents' sentiments. The information credibility has a very positive influence on respondent. Lastly it been observed that interest and time spent in news has both positive and negative influence on respondents sentiment. It depends may be on the kind of news the respondents receives.

c) Thematic analysis.

Table 2: Thematic analysis

\begin{tabular}{|c|c|c|c|c|c|}
\hline Codes & 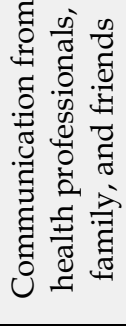 & 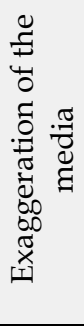 & 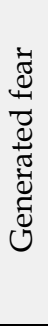 & 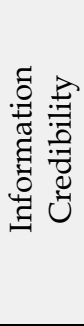 & 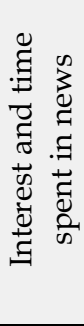 \\
\hline Awareness & 0 & 0 & 2 & 0 & 0 \\
\hline Information & 1 & 2 & 0 & 1 & 0 \\
\hline Media & 0 & 1 & 0 & 2 & 2 \\
\hline $\begin{array}{l}\text { Necessary } \\
\text { Precautions }\end{array}$ & 0 & 0 & 2 & 0 & 0 \\
\hline Precautions & 0 & 0 & 4 & 0 & 0 \\
\hline
\end{tabular}

The results of the thematic analysis show that media has a vital role in spreading information awareness regarding the necessary precautions to be followed during Covid time. The exaggeration of media has instigated the respondents' interests and time to be spent in credible news information. The fear is generated among the respondents regarding the necessary precautions to be taken to prevent the spread of the infectious disease. It has proven to be important aspect to create awareness about the deadly infection.

\section{CONCLUSION}

This paper has concluded that the reliability, credibility of the news impacts people sentiments. The research has put forward that media has a significant influences in creating the awareness about the deadly corona virus. The results of semantic analysis have indicated that community has very negative influence in spreading the information about Covid whereas exaggeration of the media has left a positive persuasion on respondents in creating awareness regarding the Covid-19. The generated fear has moderately constructive effect among people in creating awareness on the respondents' sentiments. The information credibility leaves positive influence. Besides, the thematic analysis results have showcase that media has a crucial role to play in dissemination of information about Covid-19. The exaggeration of media has positively created huge awareness for the necessary precautions to be taken during Covid. This research is quite useful to predict people sentiment and views about Covid. However, the future scope remains with larger number of audience and focussed group discussions should be held where more factors can be included with help of expert advice.

\section{REFERENCES}

Aldwairi, M., \& Alwahedi, A. (2018). Detecting fake news in social media networks. Procedia Computer Science, 141, 215-222. https://doi.org/10.1016/j.procs.2018.10. 171

Boukes, M., \& Vliegenthart, R. (2017). News consumption and its unpleasant side effect: Studying the effect of hard and soft news exposure on mental well-being over time. Journal of Media Psychology, 29(3), 137-147. https://doi.org/ 10.1027/1864-1105/a000224 
Castillo, C., Mendoza, M., \& Poblete, B. (2011). Information credibility on Twitter. Proceedings of the 20th International Conference Companion on World Wide Web, WWW 2011, 675-684. https://doi.org/ 10.1145/1963405.1963500

Chen, Y., Conroy, N. J., \& Rubin, V. L. (2015). Misleading online content: Recognizing clickbait as "false news." WMDD 2015 Proceedings of the ACM Workshop on Multimodal Deception Detection, Co-Located with ICMI 2015, 15-19. https://doi.org/ $10.1145 / 2823465.2823467$

Covid-19:Misinformation, fake news on coronavirus is proving to be contagious more lifestyle - Hindustan Times. (n.d.). Retrieved August 31, 2020, from https:/ / www.hindustantimes.com/more -lifestyle/covid-19-misinformation-fakenews-on-coronavirus-is-proving-to-becontagious/storywmKXCKjESMQIEZoyI9VJ8O.html

Du Plessis, C. (2017). The role of content marketing in social media content communities. SA Journal of Information Management, $\quad 19(1), \quad 1-7$. https://doi.org/10.4102/sajim.v19i1.866

Farajtabar, M., Yang, J., Ye, X., Xu, H., Trivedi, R., Khalil, E., Li, S., Song, L., \& Zha, H. (2017). Fake News Mitigation via Point Process Based Intervention. http://arxiv. org/abs/1703.07823

Guille, A., Hacid, H., Favre, C., \& Zighed, D. A. (2013). Information diffusion in online social networks: A survey. SIGMOD Record, 42(2), 17-28. https://doi.org/ $10.1145 / 2503792.2503797$

Jacobson, J., Gruzd, A., \& Hernández-García, Á. (2020). Social media marketing: Who is watching the watchers? Journal of Retailing and Consumer Services, 53(March). https://doi.org/10.1016/j. jretconser.2019.03.001

Jeffres, L. W., Lee, J. W., Neuendorf, K., \& Atkin, D. (2007). Newspaper Reading Supports Community Involvement. Newspaper Research Journal, 28(1), 6-23. https://doi.org/10.1177/07395329070280 0102

Mejia, C. R., Ticona, D., Rodriguez-Alarcon, J. F., Campos-Urbina, A. M., CatayMedina, J. B., Porta-Quinto, T., Garayar-
Peceros, H., Ignacio-Quinte, C., Esteban, R. F. C., Ruiz Mamani, P. G., \& TovaniPalone, M. R. (2020). The media and their informative role in the face of the coronavirus disease 2019 (COVID-19): Validation of fear perception and magnitude of the issue (MED-COVID19). Electronic Journal of General Medicine, 17(6). https://doi.org/10.29333/ejgm/ 7946

Mosinzova, V., Fabian, B., Ermakova, T., \& Baumann, A. (2019). Fake News, Conspiracies and Myth Debunking in Social Media - A Literature Survey Across Disciplines. SSRN Electronic Journal, 1, 1-17. https://doi.org/ $10.2139 /$ ssrn.3328022

Mustafaraj, E., \& Metaxas, P. T. (2017). The fake news spreading plague: Was it preventable? WebSci 2017 - Proceedings of the 2017 ACM Web Science Conference, 235-239. https://doi.org/10.1145/ 3091478.3091523

Nguyen, D. T., Nguyen, N. P., \& Thai, M. T. (2012). Sources of misinformation in Online Social Networks: Who to suspect? Proceedings - IEEE Military Communications Conference MILCOM. https://doi.org/10.1109/MILCOM.2012. 6415780

Pandey, H. K. (2020). Role of Print Media in Spreading Awareness on Coronavirus Disease ( COVID- Role of Print Media in Spreading Awareness on Coronavirus Disease ( COVID-19). Journal of Xi'an University of Architecture \& Technology, 12(4). https://doi.org/10.37896/JXAT12. $04 / 1255$

R, J., D, B., \& waran, K. (2020). Social Media Reigned by Information or Misinformation About COVID-19: A Phenomenological Study. SSRN Electronic Journal, May. https://doi.org/ 10.2139/ssrn.3596058

Reer, F., Tang, W. Y., \& Quandt, T. (2019). Psychosocial well-being and social media engagement: The mediating roles of social comparison orientation and fear of missing out. New Media E Society, 21(7), 1486-1505. https://doi.org/10.1177/ 1461444818823719

Ruchansky, N., Seo, S., \& Liu, Y. (2017). CSI: A 
Hybrid Deep Model for Fake News Detection. https://doi.org/10.1145/

3132847.3132877

S Aral, C. D. D. G. (2013). Social media and business transformation: a framework for research. Information Systems Research, 24(1), 3-13.

Sadhna, P., Gupta, S., \& Rastogi, S. (2020). Key motivators for driving work performance amid COVID-19 in developing nations. International Journal of Work Organisation and Emotion, 11(2), 105-119.

Sharma, G., \& Gupta, S. (2020). Modelling the impact of corporate sustainability on economic performance with reference to Indian financial industry. World Review of Entrepreneurship, Management and Sustainable Development, 16(3), 317-328.

Schoonenbooma, J., Burke, R., Johnson, M., \& Froehlich, D. E. (2017). Combining multiple purposes of mixing within a mixed methods research design. International Journal of Multiple Research Approaches, 10(1), 271-282. https://doi.org/10.29034/ijmra.v10n1a1 7

Slater, P. B. (2008). Established Clustering Procedures for Network Analysis. http://arxiv.org/abs/0806.4168

Tacchini, E., Ballarin, G., Della Vedova, M. L., Moret, S., \& de Alfaro, L. (2017). Some like it Hoax: Automated fake news detection in social networks. CEUR Workshop Proceedings, 1960.

Tang, J., Chang, Y., \& Liu, H. (2014). Mining social media with social theories. ACM SIGKDD Explorations Newsletter, 15(2), 20-29. https://doi.org/10.1145/2641190. 2641195

Wang, W. Y. (2017). "Liar, Liar Pants on Fire": A New Benchmark Dataset for Fake News Detection. http://arxiv.org/abs/1705. 00648

Yuan, E. (2011). NEWS CONSUMPTION ACROSS MULTIPLE MEDIA PLATFORMS: A repertoire approach. Information Communication and Society, 14(7), 998-1016. https://doi.org/10. 1080/1369118X.2010.549235

Zubiaga, A., Aker, A., Bontcheva, K., Liakata, M., \& Procter, R. (2018). Detection and resolution of rumours in social media: A survey. In ACM Computing Surveys (Vol. 51, Issue 2). Association for Computing Machinery. https://doi.org/10.1145/ 3161603 